\title{
ADAPTATION OF CONVENTIONAL RAILWAY LINES TO UPGRADED FREIGHT RAIL CORRIDOR. APPLICATION TO THE MANCHEGAN- EXTREMADURAN CORRIDOR.
}

\section{Coloma-Miró, Juan Francisco; García-García, Marta}

Department of Construction. University of Extremadura. ifcoloma@unex.es; Department of Construction. University of Extremadura.martagg@unex.es

\section{Summary}

The extension works of the Panama Canal expected in 2017 will allow the crossing of great merchant ships coming from Asian harbours. The predicted rise of freight transport in the ports of Sines and Algeciras will require a comprehensive renewal of a great part of the peninsular railway infrastructure. The Badajoz-Caceres-Madrid high speed railway designed for a mixed passengers-freight traffic, is under construction without a closing date, so a necessary adaptation of the conventional Sines-BadajozPuertollano railway line will be necessary to allow freight transport until Brazatortas and its subsequent distribution to the rest of Spain.

This research analyses infrastructure and exploitation conditions marked by European Technical Specifications for Interoperability (TSIs). Subsequently it carries out a detailed study of the current situation of the conventional Sines-Badajoz-Puertollano railway line with the aim of planning the steps required to transform this network into an upgraded freight railway line and be able to quantify and program in time the necessary investments.

For the commissioning of the $300 \mathrm{~km}$ corridor from Badajoz to Puertollano, the research concludes that it is necessary to invest $161 \mathrm{M} €$ in three years so freight train traffic of 25 t/axle can circulate over the corridor, and 80 M€ more to electrify the line and supply a train overtaking and parking post which allows the circulation of 750 meter-long trains. The cost of the upgraded railway infrastructure adds up to 640,000 €/ km which compared to the average cost of $8.51 \mathrm{M€} / \mathrm{km}$ of the Madrid-Badajoz high speed railway, allows to come to the conclusion that the investment in $1 \mathrm{~km}$ of high speed railway is equal to adapting more than $13 \mathrm{~km}$ of conventional line for the upgraded freight line.

Key Words: Railway, freight transport, construction investment. 


\section{Introduction and objectives}

The Trans-European Transport Network (TEN-T) is formed by a compound of priority lines of transport which make the communication of people and freight easier throughout Europe. The $16^{\text {th }}$ axis was a high capacity railway freight corridor with high performance which was included in this line since 2003. It came from the ports of Sines and Algeciras, it went through the Iberian Peninsula and crossed the centre of the Pyrenees through a low elevation tunnel to get to Paris. In December 2013 the European Parliament (EU, 2013) establishes a radical change in the priority core ideas of the TEN-T reducing the 30 initial main axis to 9 in the 2014-2020 period. A part of the $16^{\text {th }}$ axis, more specifically the Manchegan-Extremaduran freight railway corridor (Cofemanex), disappears as main idea of the Core Network, to become part of the Comprehensive Network, whose construction is not expected until 2050. Cofemanex is part of the Madrid-Ciudad Real-Badajoz railway line, it has $304 \mathrm{~km}$ of length and runs in a cross-wise way (from east to west) by the communities of Castilla La Mancha $(91 \mathrm{Km})$ and Extremadura $(213 \mathrm{Km})$. Cofemanex starts in Puertollano (Castilla La Mancha) and finishes in Badajoz (Extremadura) at the Portuguese border (Figure 1).

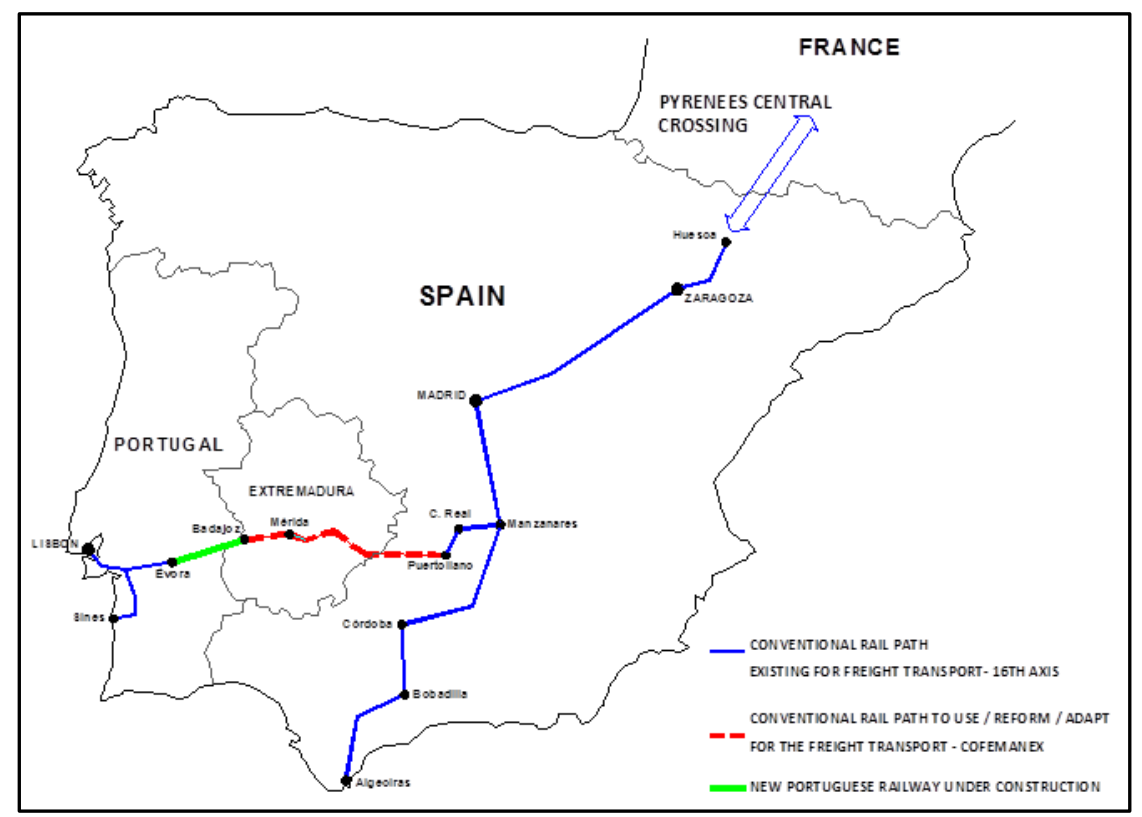

Fig. 1 Geographical zone of the Manchegan-Extremaduran Railway Freight Corridor (Cofemanex)

The close inauguration of the extension works of the Panama Canal is going to increase predictably the traffic of huge merchant ships coming from the main Asian harbours, so the ports of Sines and Algeciras, which serve as an entrance and an exit to the Iberian Peninsula, will gain lots of freight. In order to guarantee the correct transport of the products which leave the port of Sines to Europe, it will be necessary that Extremadura has a railway freight infrastructure that allows the traffic of upgraded railways.

This research analyses infrastructure and exploitation conditions marked by European Technical Specifications for Interoperability (TSIs). Subsequently it carries out a detailed study of the current condition of the conventional SinesBadajoz-Puertollano railway line with the aim of planning the steps required to transform this network into an upgraded freight railway line and be able to quantify and programme in time the necessary investments.

\section{Infrastructural and exploitation determinants in freight transport.}

\subsection{Technical Specifications for Interoperability (TSIs) of the Trans-European Transport Network (TEN-T) subsystem.}

The European Commission (EU, 2011a) establishes some Technical Specifications for Interoperability (TSIs) having to do with the Trans-European Transport Network (TEN-T) subsystem. The TSIs will apply to all new, restored, or renewed infrastructures of the current Trans-European Transport Network. According to each one of the categories of the TEN-T lines some requirements that must be achieved by the infrastructure subsystem are specified. In the TSIs categories passengers terminals, freight terminals and linking lines are included, as appropriate. In Table 1 the TSIs categories are enclosed. 
Table 1. TSI categories of line for the conventional rail infrastructure subsystem

\begin{tabular}{|c|c|c|c|c|}
\hline & \multirow{2}{*}{ TSI categories of line } & \multicolumn{3}{|c|}{ Types of traffic } \\
\hline & & Passenger traffic (P) & Freight traffic (F) & Mixed traffic $(\mathrm{M})$ \\
\hline \multirow{4}{*}{ 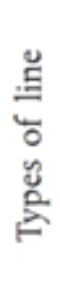 } & New core TEN line (IV) & IV-P & IV-F & IV-M \\
\hline & Upgraded core TEN line (V) & V-P & $\mathrm{V}-\mathrm{F}$ & V-M \\
\hline & New other TEN line (VI) & VI-P & VI-F & VI-M \\
\hline & Upgraded other TEN line (VII) & VII-P & VII-F & VII-M \\
\hline
\end{tabular}

Source: EU, 2011a

The Manchegan-Extremaduran railway line (Cofemanex) has been dropped from the Core Network of the TransEuropean Transport Network, to be part of its secondary Comprehensive Network. This is a group of upgraded other TEN lines with mixed traffic (passenger and freight) so the Cofemanex railway line should be inside the VII-M group. The main aim of this corridor has always been the fact of being able to become an upgraded freight corridor as it was designed in the 9 freight priority corridors (EU, 2010) over a European rail network for a competitive freight transport. In this case the Cofemanex railway line should enclose the technical specifications of the upgraded core TEN line and belongs to the V-M group.

Performance parameters for TSI categories (EU, 2011a) in the Cofemanex are:

Minimum conditions for upgraded secondary TEN lines:

- $\quad$ Minimum gauge: GA. (UNE, 2014)

- $\quad$ Load per axle: $20 \mathrm{t}$

- $\quad$ Line speed: $120 \mathrm{~km} / \mathrm{h}$.

- Maximum length of the train: $500 \mathrm{~m}$.

Minimum conditions for upgraded core TEN lines

- $\quad$ Minimum gauge: GB. (UNE, 2014)

- $\quad$ Load per axle: $22.5 \mathrm{t}$.

- $\quad$ Line speed: $160 \mathrm{~km} / \mathrm{h}$.

- $\quad$ Maximum length of the train: $600 \mathrm{~m}$.

\subsection{In-plant layout of the Cofemanex}

Coloma (2015a) develops an exhaustive study of in-plant layout of the Cofemanex. In Figure 2, maximum real speeds are compared in the railway line (Adif, 2014a) with the maximum hypothetical reachable speeds in case the limiting parameters were exclusively the ones on the in-plant layout. Figure 2 shows that the major difference in speed is produced in Castuera and Cabeza del Buey, where they are limited to $50 \mathrm{~km} / \mathrm{h}$ because of the condition of the railway, being possible to reach $140 \mathrm{~km} / \mathrm{h}$ per in-plant layout. Therefore it is the stretch that needs more immediate attention. It is the railway zone which is more damaged, with railway wooden sleepers and early XX century rails. The railway switches are all manual or mechanic and the block system of the line is telephonic. The worst zone regarding in-plant layout is situated between the limit of the province and Cabeza del Buey, where the radius projected allows maximum speeds between $80 \mathrm{~km} / \mathrm{h}$ and $100 \mathrm{~km} / \mathrm{h}$. The other complicated zone is located between Zarza de Alanje and Merida where the radius projected allows maximum velocities of $110 \mathrm{~km} / \mathrm{h}$. 


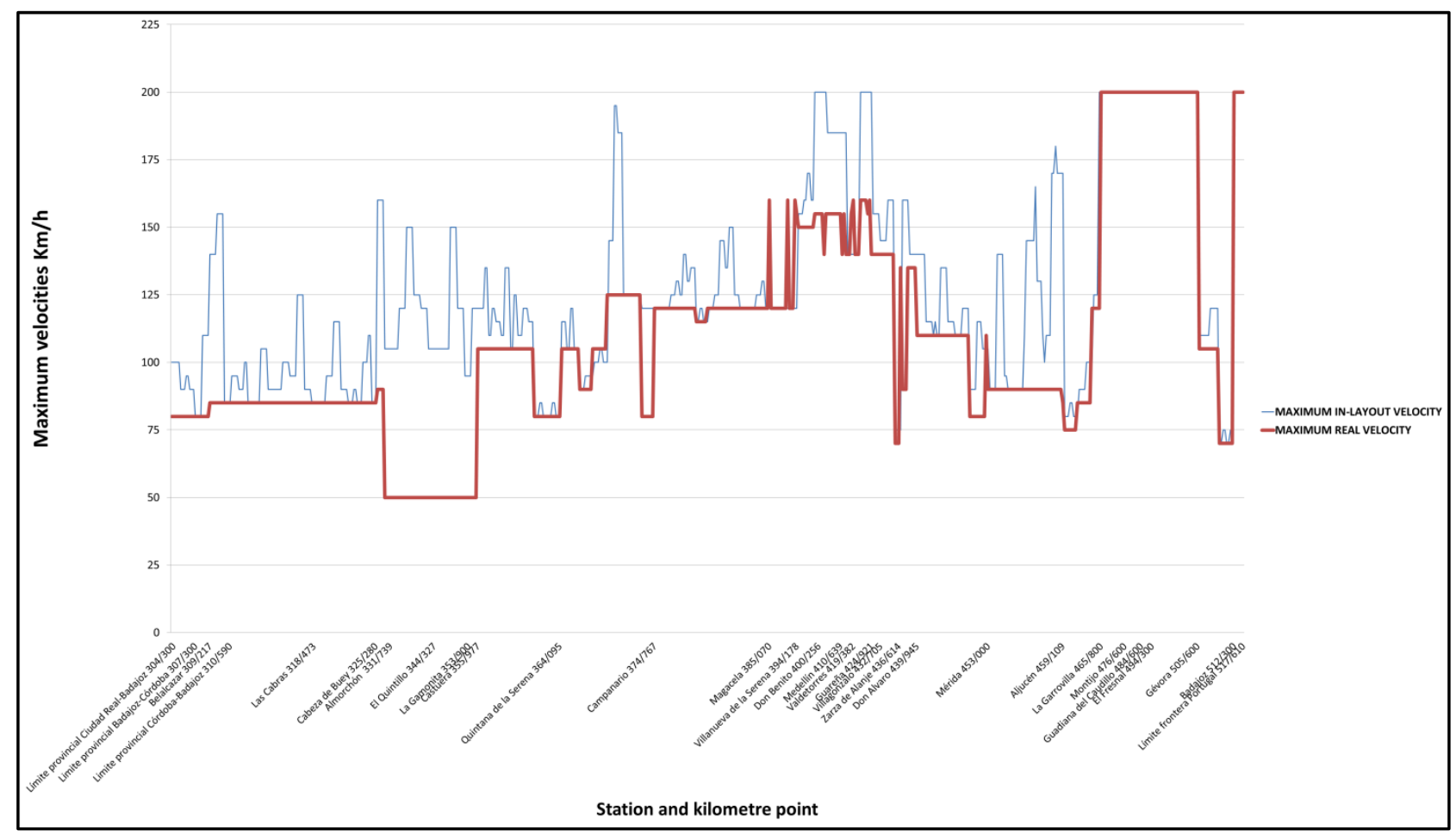

Fig. 2 Cofemanex: Extremaduran stretch. Differences between maximum speeds $(\mathrm{km} / \mathrm{h})$ which can be reach according to in-plant layout and maximum real allowed speeds of the Cofemanex.

\subsection{Elevation layout of Cofemanex}

The longitudinal profile of the Cofemanex is very smooth with little peaks being its average slope $0.59 \%$. The most used freight locomotive by Renfe in the Cofemanex is the diesel series 333.3. The biggest characteristic slope in the whole stretch is $18.3 \%$, which guarantees the transport of trains up to 1,100 tonnes of weight along the line (Adif, 2014b). Coloma (2015b) carries out an exhaustive study of the elevation layout of the Cofemanex. Figure 3 shows a comparison between maximum allowed speeds in the railway line (Adif 2014a) and hypothetical maximum reachable speeds in the case that the limiting parameters were exclusively the ones in the elevation layout.

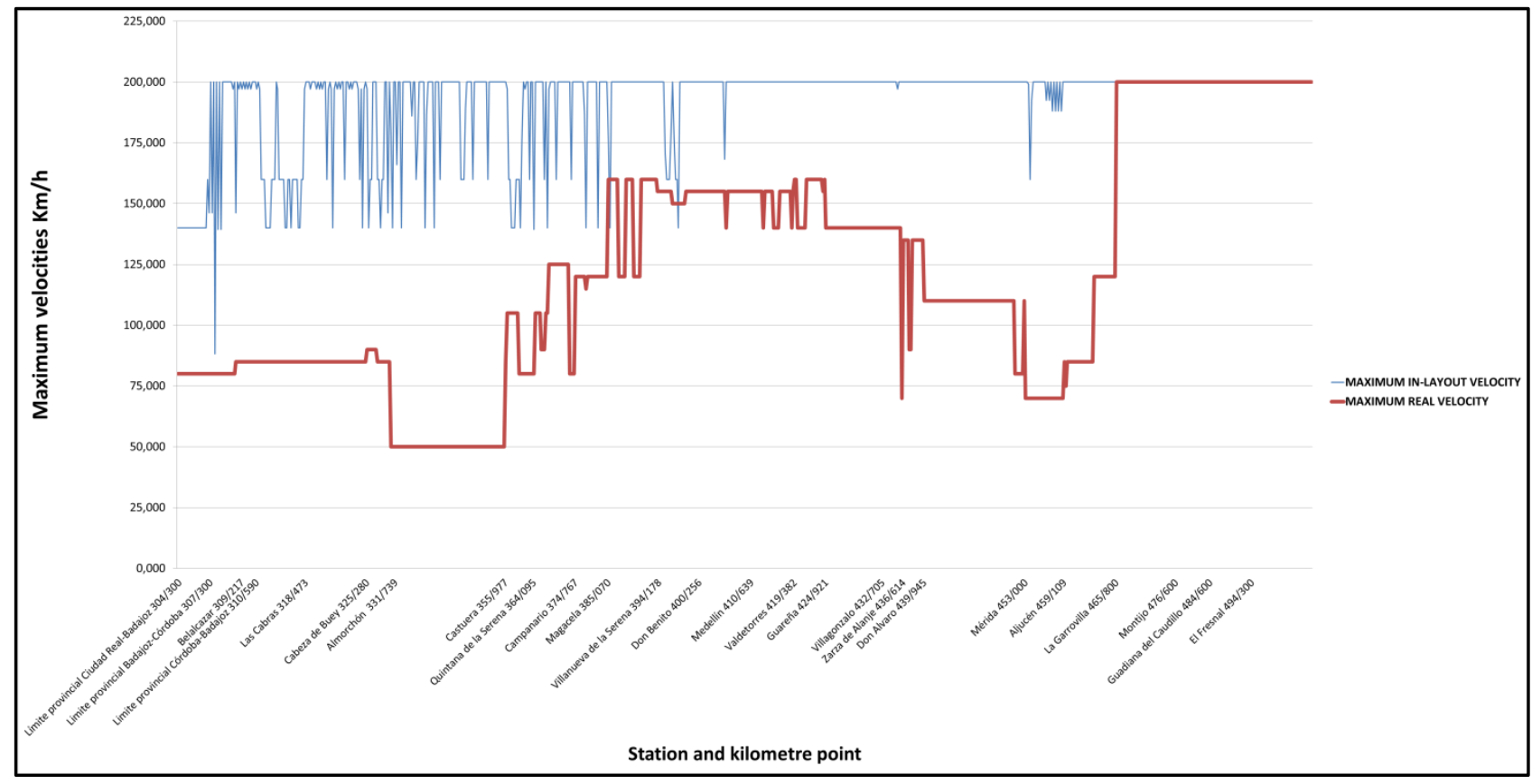

Fig. 3 Cofemanex Extremaduran stretch. Differences between maximum velocities $(\mathrm{km} / \mathrm{h})$ which can be reached according to the elevation layout and maximum real allowed velocities of the Cofemanex. 
The maximum slope of $18.30 \%$ is located in the $\mathrm{km} 306.356$ (near Belalcazar-Cordoba) towards Puertollano in a length of $61 \mathrm{~m}$. There also exists a slope of $17.80 \%$, towards Badajoz, that is $100 \mathrm{~m}$ long at $\mathrm{km} 300.000$ (near Gualdamez-Los Pedroches-Ciudad Real). Thus, the Cofemanex railway corridor has every parameter in its outline according to the normative (Adif, 1998) to have a maximum speed of $160 \mathrm{~km} / \mathrm{h}$ and to be in the European TSIs included in the V-M group.

\subsection{Gauges in the structures of the Cofemanex}

Each infrastructure administrator defines its own structure gauges. Adif (1998) requires a minimum vertical gauge for superior tunnels of $7 \mathrm{~m}$, and a horizontal gauge of $13.30 \mathrm{~m}$. These structure gauges contemplate the necessary space to electrify and double the line, if it were needed. The gauges are superior from those required by the TSIs (UNE, 2014) which are enclosed below:

- $\quad$ Upgraded secondary lines in the TEN-T network require GA gauge

- $\quad$ Already existing main lines, require GB gauge

- $\quad$ New main lines to be built require GC gauge

In this research, an "in situ" measurement of all the gauges of the structures over the Cofemanex has been carried out. These structures are the ones which will define the future of freight transport, the future of the electrification of the line or the future doubling of the platform. Coloma (2015c) creates a file for each of the structures with the vertical and horizontal gauge data and the more important characteristics of the infrastructure, as well as its location, coordinates, state of preservation and pictures of them.

To determine the vertical gauge of each structure, measures are taken at least in 4 different points and always where the structure gauge seems to be smaller. Normally, it will be the inferior part of the beam or slab of the bridge. Vertical gauges measured are always minimum and free from the inferior part of the beam until the upper part of the railway. The measures of the horizontal gauges are taken in a similar way to the vertical ones. 2 measuring points are taken as minimum and always over the elements which condition this gauge as it is the case of abutments or piers in the bridge. The gadget used to measure has been the distance laser meter Kolida PD-56. The technical specifications are the following:

\footnotetext{
- $\quad$ A reach of $0.05-60 \mathrm{~m}$ and a measuring precision of $\pm 1.5 \mathrm{~mm}$

- Minimal visualized unit of $1 \mathrm{~mm}$ and working temperature range of $-10 \mathrm{a}+50^{\circ} \mathrm{C}$

- $\quad 135 \times 45 \times 31 \mathrm{~mm}$ dimensions and a weight of $0.145 \mathrm{~kg}$
}

In Figure 4 the gauges of the Cofemanex structures are represented. To classify the vertical gauges we take as a minimum gauge the GEAC16 (UNE 2014). This gauge is the normalized as the GC by the "International Union of Railways" (UIC), adapted to the conventional width $(1.688 \mathrm{~mm})$. It corresponds with the TSIs requirements for the mixed lines which belong to the main trans-European network and those of new construction (IV-M). The vertical gauge required for this section is $4.70 \mathrm{~m}$. All the gauges below this value will be drawn in red because they don't follow the European TSIs. To electrify a railway line, UNE (2014) establishes the value of $6.75 \mathrm{~m}$ for lines with a maximum speed of $160 \mathrm{~km} / \mathrm{h}$. All the gauges over $6.74 \mathrm{~m}$ of vertical free span will be understood as stretches which could be electrified and will be drawn in green. The gauges which are between $4.70 \mathrm{~m}$ (GEAC16) and the $6.75 \mathrm{~m}$ fulfil the requirements of the European TSIs, nevertheless they forbid the possibility of electrifying the line in that same structure. In the case of developing the electrification of the line, these structures must be modified.

In Figure 5 the horizontal gauges are classified according to Adif (1998), where $9.0 \mathrm{~m}$ is established as a width for the sole railway and $13.30 \mathrm{~m}$ for double railway. Gauges below $9.0 \mathrm{~m}$ show the nonfulfillment of the normative for a sole railway and therefore will be drawn in red. Gauges superior to $13.30 \mathrm{~m}$ show the possibility of multiplying the railway if the case required it to and therefore will be drawn in green. The rest of gauges fulfil the current requirements of Adif for a sole railway although if a duplication of the railway is required it will be necessary to modify these structures. 


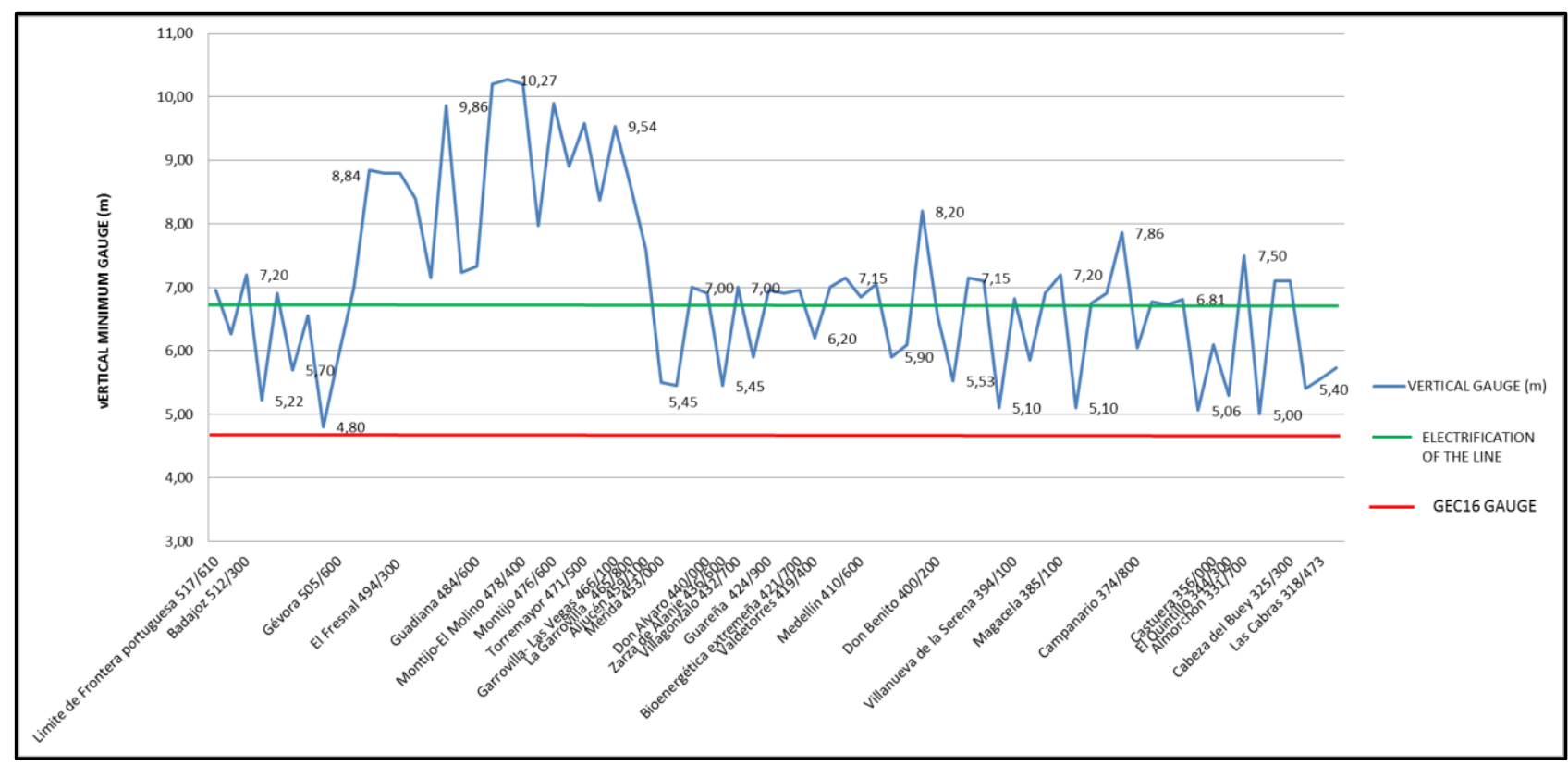

Fig. 4 Minimum vertical gauges in the Extremaduran structures of the Cofemanex

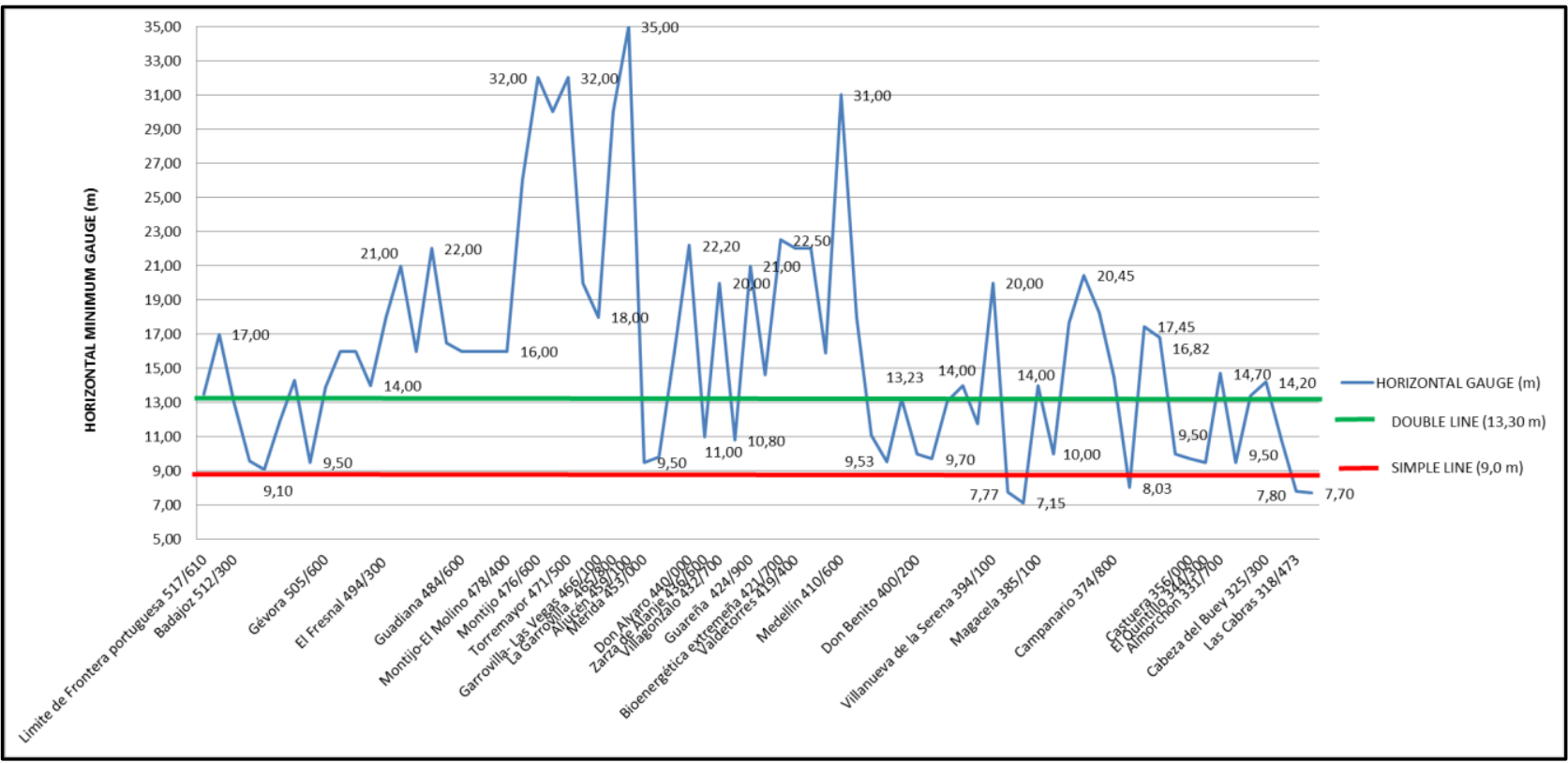

Fig. 5 Minimum horizontal gauges in the Extremaduran structures of the Cofemanex

The existing gauge structures in the Extremaduran stretch of the Cofemanex are adequate for the traffic of an upgraded freight train. Nevertheless, not all of them have whether enough gauge to electrify the line, nor the possibility of doubling it. It's important to highlight the gauges that are part of the recently created structures with the characteristics of the high speed railway, all of them over $7.0 \mathrm{~m}$ high and $13.30 \mathrm{~m}$ wide. These gauges allow a double railway and the electrification of the line. The remaining structures with more strict edges allow freight traffic in general, the electrification of the railway and even in many cases its duplication.

In the city surroundings the structures are older and the gauges tighter. Out the 74 structures that we have studied, 47 $(63.5 \%)$ allow the electrification of the railway because of the vertical gauges which are over $6.75 \mathrm{~m}$, and 27 (36.5\%) would need to be rebuilt for its electrification, due to the fact that they don't reach that required minimum gauge.

Regarding the possibility of doubling the line, 47 structures (63.5\%) allow double railways because the horizontal width is over $13.30 \mathrm{~m}$. 22 out of 74 (29.7\%), have the width of the railway which is stablished by Adif (1998) (9 m), and the other $5(6.8 \%)$ don't reach the $9 \mathrm{~m}$ stablished by the normative.

All the structures are included in the GEC16 structure gauge, meaning that they surpass the $4.70 \mathrm{~m}$ from the bottom part of the structure to the upper part of the railway (running surface). The structure of the road of Montijo in the $\mathrm{km}$ 507.300 with $4.80 \mathrm{~m}$, marks the vertical inferior gauge of all the structures. The rest of the structures fulfil widely the 
minimums marked in the outline of the GEAC16 structure gauge. The oldest structures are more adjusted to this gauge such as Almorchón (5.00 m gauge), Castuera (5.06 m), the excavation of "Padre Taroconte Avenue of Badajoz" (5.22 $\mathrm{m}$ ) and the tunnel of "Las Cabras" $(5.56 \mathrm{~m})$. Therefore, the structures of the Cofemanex, not only fulfil the requirements of the TSIs, but a lot of them are also over $6.75 \mathrm{~m}$ of gauge and allow a future electrification of the railway. The horizontal gauges in general, are also sufficient to fulfil the requirements of a sole platform marked by Adif (1998). The structures in the urbanization "Las Mimosas" in Villanueva de la Serena (7.7 m of gauge), the road of "Los Palos" (8.08 $\mathrm{m})$ and the tunnel of "Las Cabras" $(7.70 \mathrm{~m})$ are the only ones that have a free space inferior to the $9 \mathrm{~m}$ required by the normative.

There also exists a wide range of structures which fulfil the requirements marked by Adif (1998) for the double railway $(13.30 \mathrm{~m})$. These structures wouldn't have to be modified in case they required a doubling of the line. Between Merida and Badajoz, the works on the platform of the high speed railway have renewed the existing structures building new ones with enough gauge to double the platform of the railway if it were necessary.

\subsection{The superstructure of the Cofemanex.}

In figure 6 we enclose the current condition of the superstructure of Cofemanex.

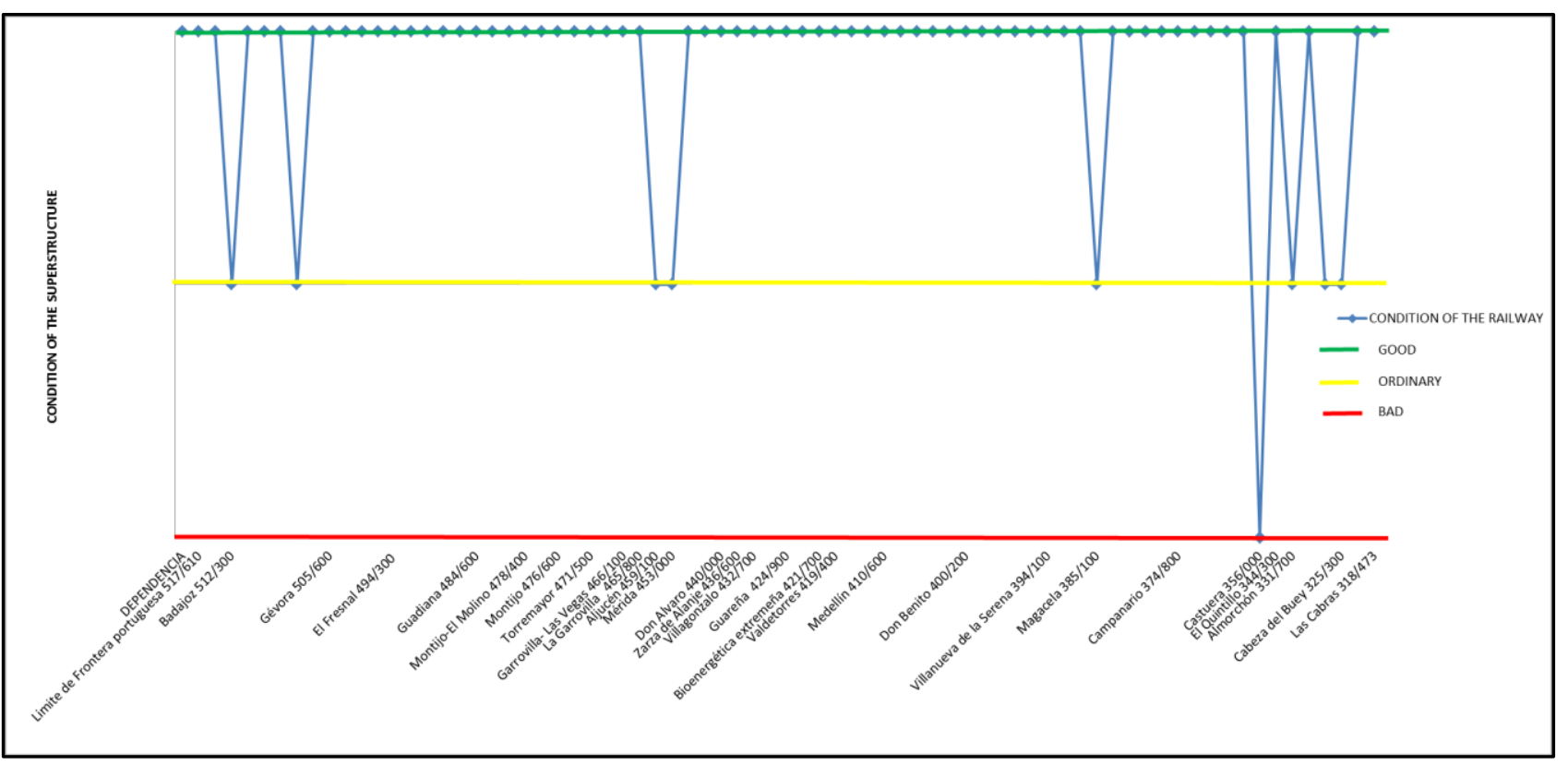

Fig. 6 Current condition of the superstructure of Cofemanex

Three condition ratings of the railway are created according to the following criteria:

Red (BAD): Wooden sleepers, rigid fastening and short bar forcing the train to reduce the speed to more inferior values to those catalogued in the Maximum Speed Chart of the line (Adif, 2014a).

Yellow (ORDINARY): Bi-block sleepers of any kind. RS sleepers, J-2 or P-2 fastening system or a BR-94 sleeper with Nabla fastening system. This type of superstructure blocks the traffic of freight trains carrying 25t/axle and trains which circulate over $160 \mathrm{~km} / \mathrm{h}$.

Green (GOOD): Sole concrete sleepers. Vossloh fastening system with an elastic SKL-1 clip. This kind of structure is the chosen one so the trains can circulate at $160 \mathrm{~km} / \mathrm{h}$, or even, if it has the appropriate rolling material, it could reach $200 \mathrm{~km} / \mathrm{h}$. Overall if it has PR-01 or PR-90 multipurpose sleepers, TSIs are fulfilled and in the near future the width of the railway could be adapted to the international width $(1,435 \mathrm{~mm})$.

Out of the 301.901 kilometres which the corridor has, $195.178 \mathrm{~km}(64.22 \%)$ have the "BAD" superstructure, $33.176 \mathrm{~km}$ $(10.92 \%)$ have the "ORDINARY" one, and the 75.547 kilometres left $(24.86 \%)$ have the "GOOD" superstructures.

The stretches which are "BAD" hamper the circulation of freight trains of a certain weight (limited to a maximum of 10t/axle) and the speeds are reduced to values which can be of $50 \mathrm{~km} / \mathrm{h}$. In some stations that have old switches, the speeds are reduced to $30 \mathrm{~km} / \mathrm{h}$, as in Belalcazar (Córdoba). These stretches are generally speaking the ones which have wooden sleepers and rigid fastening systems, with railways from the beginning of the XX century. They should be 
renewed urgently to be able to guarantee the circulation of a freight train on the line and even more if we pretend it to be upgraded.

The stretches which have its superstructure in a "ORDINARY" condition, have normally undergone some kind of renovation, but not good enough to change its condition to "GOOD". Normally, they are zones with bi-block sleepers that whether were installed in the 70s, or were installed earlier this century to fix the deficiency of the wooden sleepers and the railways of $45 \mathrm{~kg} / \mathrm{m}$. Taking into account bi-block sleepers cannot support UIC-60 rails, don't allow speeds over $160 \mathrm{~km} / \mathrm{h}$ and can't bear more than 25 t/axle as the TSIs states for this freight trains in main lines, they need to be gradually substituted little by little when it is economically possible. This type of superstructure allows conventional freight train circulation (up to 22.5 t/axle) but not upgraded freight trains ( $25 \mathrm{t} / \mathrm{axle}$ ). Therefore, its renovation is not urgent even though we should take into account the medium term actions.

Lastly, the "GOOD" conditions of some railways guarantee the circulation of upgraded freight trains, with a little hint. From "La Garrovilla" to "Badajoz" the railway possesses UIC-60 and sole multipurpose sleeper which makes it easier for trains to circulate at $200 \mathrm{~km} / \mathrm{h}$ and $25 \mathrm{t} /$ axle of weight. Plus, the possibility of changing the international width when it is required to do so. The rest of the superstructure which is in "GOOD" shape has sole multipurpose sleepers and allows the modification of the international width. Nevertheless, the rails used are UIC-54 which limits the possibility of 25 t/axle trains circulation.

\subsection{Stations and train overtaking and parking post}

In order to have a fluent circulation of passengers and freight, it is necessary that the railway has enough stopping points that allow the necessary overtakes not to mess with the correct progress of the faster trains. In the Cofemanex there are enough stations where these parkings and overtakes can happen. Nevertheless, the lengths of the allowed trains in the Cofemanex are of $400 \mathrm{~m}$ in normal circulation conditions and $460 \mathrm{~m}$ in special circulations.

The ITIs stablished for mixed traffic a minimum length of $500 \mathrm{~m}$ for the adaptation of lines included in the Comprehensive Network, $600 \mathrm{~m}$ for the adaptation of the main networks, and $750 \mathrm{~m}$ for the construction of new lines included in the Core Network. This means that the length of stations and halts which allow overtakes and parking of trains, are not long enough when speaking about TSIs. It would be necessary to adapt the different stations and halts to provide them with a longer length and fulfil the European normative. Analysing all this values, it can be concluded that the length of the freight trains which are allowed in the Cofemanex is being shortened, but the unfulfillment of this requisite, doesn't hamper the circulation of freights over it. It is a subject that is desirable and good but not indispensable for the circulation of freight in the corridor.

\subsection{Rolling stock}

The locomotives used in Cofemanex for freight transport are from the 333.3 series which allow transporting freight of more than 1,000 $\mathrm{t}$ with maximum slope of $20 \%$ (which doesn't exist in Cofemanex) and almost 2,000 $\mathrm{t}$ for maximum slopes of $10 \%$. Therefore they are adequate values for freight transport which is currently taken place in this line, and are prepared to carry out the transportations demanded in the near future.

\subsection{Signposting, security systems and types of block systems that exist in the Cofemanex}

The security facilities and existing blockages in the Cofemanex are extremely varied. There is between Merida and Badajoz a modern system of automatic block signalling (ABS) via circuits and centralised traffic control. It also has 200 Digital ASFA and luminous signalling. It's very modern control systems that avoid it's saturation.

In the next level, we find in the Cofemanex the "automatic release block signalling", through the "axle counter". We have it between Villanueva de la Serena-Mérida and between Barazatortas-Puertollano. They also have the ASFA system as an automatic system of train protection and in the case of Villanueva de la Serena until Mérida with "trainland" as a communication system. The signposting in both cases is luminous. It is a block system suitable for the traffic that takes place in this kind of railway. Only between Brazatortas-Puertollano it would be good to introduce a train-land system to improve the communication systems between the station and the train.

The problem lays in the rest of the stretch of the Cofemanex which has a telephonic block system, ASFA and mechanical signalling. This is the stretch between Villanueva de la Serena and Brazatortas (161.5 km) where the control 
of the traffic can only be carried out between stations and this produces a constant saturation of the line. Thus, to be able to clear the line and introduce the necessary control for passenger and freight trains circulation that Cofemanex demands, it is necessary to substitute the telephonic existing block in this $161.5 \mathrm{~km}$ and giving it a more modern block system based on little stretches with "axle counter" like the one between Mérida and Villanueva de la Serena. To guarantee individual organisation between the train and the station a minimum train-land system must be installed along these $161.5 \mathrm{~km}$. The existing mechanical signposting must be renewed over time as well by the one that is being currently used (luminous).

About the automatic protection train systems it is necessary to remember that TSIs shows the necessity of installing the ERTMS system in all the lines of the Core and Comprehensive Network. Nevertheless, even when this disposition should be taken into account for medium term, the ASFA is a sufficiently effective protection system to guarantee the security of the trains which circulate in the Cofemanex, no matter passenger or freight train. This improvement must be regarded as a medium term investment and not as a required immediate investment.

\subsection{Level crossing in the Cofemanex}

In the Cofemanex there exist 13 type A level crossings, 3 type B, 5 type $\mathrm{C}$ and 2 private ones. The elimination of the level crossing is not necessarily an urgent action, because they don't hamper the correct circulation of freight trains. Despite the security improvements that arise from their elimination cause that they need to be taken into account in the ensemble of actions that, for the medium term, are developed in the corridor. It is important to highlight that between Don Benito and Badajoz there have been done all the necessary works for the elimination of all the level crossings that existed between these two towns. There would only be left the urban level crossing of Don Benito which is located near the station of Aljucén and the level passing that exists between Badajoz and the Portuguese border near the place where the southwest European Logistics Platform is located.

\subsection{Power supply of the Cofemanex}

In Spain, the electrifying voltages for long-distance lines are of 3,000 V in continuous current (conventional lines) and $25 \mathrm{kV}$ in alternating current (high speed lines). According to the TSIs the alternating current system of $25 \mathrm{kV}-50 \mathrm{~Hz}$, must be the desired power supply for compatibility reasons with the power generation and distribution systems, and equipment normalization of the substations. Nonetheless, due to the high costs of the necessary investments to migrate from other system voltages to the $25 \mathrm{kV}$ and the possibility of using multipurpose traction units, the continuous current at $3 \mathrm{kV}$ is allowed.

M. Fomento (2011) points out that as a general idea, the construction of new lines and the electrification of the already existing ones, everything will be planned with a $25 \mathrm{kV}$ AC voltage. Nonetheless, he also adds the idea that the electrification in $3 \mathrm{kV}$ DC will be accepted in stretches with a reduced length which are a continuation of existing networks, if and when this is authorized, specifically, by the Rail Infrastructure Management Team.

In any case, it is necessary that when the catenary of $3 \mathrm{kV} \mathrm{DC}$ is installed, isolation elements should be used allowing its later transformation to $25 \mathrm{kV}$ AC. Moreover when the initial exploitation is realised in a 1,668 mm width, the design will be built so its later transformation is possible, to allow the third railway exploitation or in the standard European width.

The Puertollano-Ciudad Real stretch is currently electrified as the great part of the ordinary lines in Spain, meaning 3,000 V DC. The Cofemanex railway corridor is not currently electrified. The adaptation for the Cofemanex should be done by 3,000 V DC with isolation elements which allows its later transformation to $25 \mathrm{kV} \mathrm{AC}$.

The catenaries used depend on the maximum speed of the track. For the Aljucén-Badajoz stretch it would be the CA220 and between Aljucén-Puertollano it would be the CA-160. Traction substations are placed according to the traffic that every line has on every stretch. In interurban zones it normally oscillates between 10 and $20 \mathrm{~km}$. With the Cofemanex traffic characteristics, it could be spaced $20 \mathrm{~km}$.

The experience obtained in similar lines, leads to the thought that a $3,000 \mathrm{~kW}$ of voltage per traction substation should be more than enough for the correct operating of the Cofemanex. This power supply guarantees the circulation of two or at least three trains between substations, so, even without having a deeper analysis of the line, they are huge security 
values. 3,300 kVA electric transformers are needed in traction substations of the conventional line to generate this power.

Extremadura generates its own electric power with its own renovable sources. It produces 5,485 Gwh with renovable sources and needs for itself to function only 4,477 Gwh. The rest of the electric power produced (21,342 Gwh) is given to other regions. The way to obtain the necessary energy in the electric supply of the Cofemanex, would be always done by obtaining power from Extremaduran renovable sources of energy such as hydraulic, photovoltaic, solar thermal energy or biomass energy.

The electrification of the Badajoz-Merida line is urgently needed, in order to have an alternative track for freight apart from the upgraded electric corridor from Portugal. This would allow Aljucén to connect with the upgraded mixed Extremaduran corridor to Madrid o Caceres, or continue from the station of Merida in diesel provisionally until Puertollano on the Cofemanex.

\subsection{Capacity of the Cofemanex}

The mechanical signposting and the telephonic block system in a great part of the Cofemanex, make its lines to be occupied over $80 \%$ of its maximum capacity, therefore there are systematic problems about its overuse. To be able to clear the line and introduce the necessary control for passenger and freight train circulation which the Cofemanex needs, it is necessary to substitute the current telephonic block system between Villanueva de la Serena and Brazatortas, and give it a more modern block system based in small stretches with "axle counter" just like the one between Merida and Villanueva de la Serena.

To guarantee individual communication between the train and the station the train-land line must be installed as well along these $161.5 \mathrm{~km}$. The existing mechanical signposting should be progressively be substituted for luminous signs which are the ones being used currently.

\section{Necessary actions in the Cofemanex. Working steps.}

In this research an exhaustive and complete analysis of the Cofemanex has been carried out. In it, all the infrastructural and exploitation determinants necessary to be able to transport passengers and freight have been analysed. The necessary actions are divided in two main steps according to their priority:

\subsection{1st Phase. The commissioning of the freight corridor.}

The actions which are necessary for the comissioning of the Cofemanex are:

\subsubsection{Improvement of the superstructure.}

- $\quad$ Merida -Aljucén. Integral renovation of the railway with concrete multipurpose sleepers and UIC-54 railway. Recently taken care of in September 2014. railway.

Castuera-Cabeza del Buey. Integral renovation of the railway with concrete multipurpose sleepers and UIC-54

- $\quad$ Cabeza del Buey- Brazatortas. Integral renovation of the railway with concrete multipurpose sleepers and UIC54 railway. Preparation and improvement of the infrastructure.

- $\quad$ Brazatortas-Puertollano. Integral renovation of the railway with concrete multipurpose sleepers and UIC-54 railway.

\subsubsection{Improvement of block and security systems in the Cofemanex.}

Villanueva de la Serena-Brazatortas. The installation of the automatic release block with centralised traffic control (CTC) and a train-land communication system.

\subsubsection{Electrification of the line}

Electrification of the Badajoz-Mérida line with a voltage of 3,000 V DC and catenary of CA-220. 


\subsubsection{Improvement of the logistics installations}

It is included the first urbanization phase of the Southwest European Logistics Platform in Badajoz and the first phase in the railway connections of said platform and of the Expaciomerida. The Junta de Extremadura started this works in December 2014.

\subsection{2nd Phase. Upgraded freight train. Electrification of the line.}

Once this Cofemanex service is given, the aim is to transform it into an upgraded freight train. For this, it is necessary to do the following actions:

- $\quad$ Electrification of the line. Preparing structures giving them enough gauge to be able to electrify them, and the electrification of the Merida-Puertollano line with a voltage of 3,000 V DC and catenary of CA-160.

- Improvements in the logistics installations. 2nd phase in the Southwest European Logistics Platform, Expaciomerida and the adaptation of "stations and train overtaking and parking post" so trains up to $750 \mathrm{~m}$ long can overtake.

- Other complementary works. Elimination of the level crossings and modification to the international width $(1,435 \mathrm{~mm})$.

\section{Investment programme.}

\subsection{1st Step. The commissioning of the freight corridor. 2014-2016 Period}

The commissioning of the Cofemanex is expected in 2017, thus all the necessary investments must be done in between the years 2014-2016. Table 2 shows the cost of the improvement of the superstructure of the Cofemanex.

Table 2. Cost of the improvement of the superstructure of the Cofemanex

\begin{tabular}{|c|c|c|c|c|c|}
\hline STRETCH & INITIAL km & FINAL km & $\begin{array}{c}\text { STRECH } \\
\text { LENGHT }(\mathrm{Km})\end{array}$ & ESTIMATE & $\operatorname{cosT} / \mathbf{k m}$ \\
\hline Puertollano/Brazatortas & 213.700 & 232.928 & 19.228 & $7,000,000.00 €$ & $364,052.42 €$ \\
\hline Brazatortas-Veredas/El Madroñal & 232.928 & 260.300 & 27.372 & $17,534,901.89 €$ & $640,614.57 €$ \\
\hline El Madroñal/Guadalmez-Los Pedroches & 260.300 & 293.800 & 33.500 & $21,890,122.08 €$ & $653,436.48 €$ \\
\hline Guadalmez/Cabeza de Buey & 298.180 & 325.042 & 26.862 & $16,569,021.62 €$ & $616,820.10 €$ \\
\hline Cabeza de Buey/Castuera & 325.042 & 355.562 & 30.520 & $18,642,367.30 €$ & $610,824.62 €$ \\
\hline Mérida/Aljucén & 453.000 & 459.100 & 6.100 & $1,580,000.00 €$ & $259,016.39 €$ \\
\hline TOTAL FOR THE UPGRADED RAILWAY & & & & $83,216,412.89 €$ & \\
\hline
\end{tabular}

- $\quad$ Renovation of the railway. For the commissioning of the freight corridor it is necessary to make an integral renovation of several stretches in the corridor. The Merida-Aljucén stretch has recently been adapted in September 2014. The integral adaptation means the substitution of the existing wooden sleepers or bi-block sleepers for a new sole multipurpose one. It's necessary the substitution of the rail of $45 \mathrm{~kg} / \mathrm{m}$ for a UIC-54 one. It also includes the adaptation of the edges and cleaning or building of current drainage systems.

Signposting, security and block system installation. The estimation of the installation of automatic release block with CTC and train-land system between Villanueva de la Serena and Brazatortas (161.5 km) reaches the cost of $18.2 \mathrm{M} €(112,693 € / \mathrm{km})$.

Electrification of the railway. The electrification of the Badajoz-Aljucén stretch $(53.2 \mathrm{~km})$ to $3,000 \mathrm{~V}$ DC and CA-220 reaches the cost of $18.6 \mathrm{M} €(349,624 € / \mathrm{km})$. The electrification of the Aljucén-Merida stretch $(6.1 \mathrm{~km})$ would 
be done as well with 3,000 V DC, but CA-160. The investments reaches up to $1,772,330.6 €(290,546 € / \mathrm{km})$. The total investment predicted to electrify the line is $20,372,330.6 €$

- Logistics installations. The urbanization of the 1st Phase in the southwest European Logistics Platform has a cost of 24,95 M€. The railway connections reach up to $14,454,810.52 €$.

In Table 3 we enclose a summary of all the actions of the first step expected in between 2014-2016€.

Table 3. Investments programme of the Cofemanex. The 1st Phase. 2014-2016 Period

\begin{tabular}{|c|l|r|}
\hline \multicolumn{3}{|c|}{ COFEMANEX. Ist PHASE INVESTMENTS. 2014-2016 PERIOD } \\
\hline 1 & Railway renovation & $83,216,412.89 €$ \\
\hline 2 & Signposting, security and block sytem installation & $18,200,000.00 €$ \\
\hline 3 & Railway electrificaction & $20,372,330.60 €$ \\
\hline 4 & $\begin{array}{l}\text { Logistics installations. European Southwest Logistics } \\
\text { Platform }\end{array}$ & $24,950,000.00 €$ \\
\hline 5 & $\begin{array}{l}\text { Logistics installations. Railway connections of European } \\
\text { Southwest Logistics Platform and Expaciomérida }\end{array}$ & $14,454,810.52 €$ \\
\hline & TOTAL INVESTMENT FOR THE FIRST PHASE OF THE \\
COFEMANEX & $161,193,554.01 €$ \\
\hline
\end{tabular}

The necessary total investment in this first phase for the commissioning of the railway freight corridor has a total cost of $161,193,554.01 €$.

\subsection{2nd Phase. Upgraded freight train. Electrificarion of the line. 2017-2021 Period}

The second phase is meant to be carried out between 2017-2021, once the commissioning of the freight corridor has taken place.

69.527.669,40 € $(290.546 € / \mathrm{km})$ was calculated as a necessary investment For the adaptation of the gauge from the structures and the electrification of the Merida-Puertollano line $(239.3 \mathrm{~km})$ with a 3,000 V DC voltage and CA-160.

For the adaptation of the "stations and train overtaking and parking post" and the rest of railway connections the following investments are predicted:

- $\quad$ Logistics Platform railway connection, 2nd Phase. 5.79 M€

- $\quad$ Railway connections of Expaciomérida 2nd Phase. 4.22 M€

The total amount for the railway connections would be 10.01 M€.

Table 4 includes a summary of all the actions in the 2nd phase of the adaptation of the Cofemanex to an upgraded freight railway corridor between 2017-2021.

Table 4. Investment programme in the Cofemanex. 2nd Phase. 2017-2021 Period

\begin{tabular}{|c|l|r|}
\hline \multicolumn{3}{|c|}{ COFEMANEX.2nd PHASE INVESTEMENTS. 2017-2021 PERIOD } \\
\hline 1 & $\begin{array}{l}\text { Adaptation of the structures and electrification of the } \\
\text { railway }\end{array}$ & $69,527,669.40 €$ \\
\hline 2 & $\begin{array}{l}\text { Adapatation of the trains overtaking and parking post and } \\
\text { the 2nd phase of the Southwest European Logistics Platform } \\
\text { and EXpaciomerida railway connection }\end{array}$ & $10,010,000.00 €$ \\
\hline & $\begin{array}{l}\text { TOTAL INVESTMENT FOR THE SECOND PHASE OF THE } \\
\text { COFEMANEX }\end{array}$ & $\mathbf{7 9 , 5 3 7 , 6 6 9 . 4 0 €}$ \\
\hline
\end{tabular}

This work is licensed under a Creative Commons Attribution-NonCommercial-NoDerivatives 4.0 International License (CC BY-NCND 4.0). 
The necessary investments in the 2 nd phase to achieve an upgraded railway freight corridor gives a total of $79,537,669.40 €$.

Table 5 includes the overall compound of all the actions to transform the Cofemanex in an upgraded freight railway corridor.

Table 5. Global investment programme of the Cofemanex. 2014-2021 Period

\begin{tabular}{|c|l|r|}
\hline \multicolumn{2}{|c|}{ INVESTMENTS SUMMARY IN THE COFEMANEX } \\
\hline 1 & $\begin{array}{l}\text { Ist Phase. Commissioning of the hreight railway corridor. } \\
2014-2016 \text { Period }\end{array}$ & $161,193,554.01 €$ \\
\hline 2 & $\begin{array}{l}\text { 2nd Phase. Upgraded freight railway train. Electrification } \\
\text { of the line. 2017-2021 Period }\end{array}$ & $79,537,669.40 €$ \\
\hline & \multicolumn{2}{|l|}{\begin{tabular}{l}
$\mathbf{2 4 0 , 7 3 1 , 2 2 3 . 4 1} €$ \\
\hline
\end{tabular}}
\end{tabular}

\section{Conclusions.}

Transport enables economic growth and job creation, therefore, it must be sustainable in the light of the new challenges which are discussed. Since the 2001 White Paper on transport (EU, 2001) a lot of progress has been achieved. TransEuropean transport networks (financed through TEN-T, Structural Funds and the Cohesion Fund) have contributed to territorial cohesion and the building of high-speed railway lines. International ties and cooperation have been strengthened. A lot has also been done to enhance transport's environmental performance. The challenge is to break the transport system's dependence on oil without sacrificing its efficiency and compromising mobility.

The new White Paper of transport (UE, 2011b) has taken as an aim the progressive elimination of the conventional propulsion vehicles of the cities by 2050 , and a change of a $50 \%$ in passengers medium-distance routes, and freight railway long-distance routes for different transport methods for that same year. The transport must use less and cleaner energy, exploit in a better way its infrastructure and reduce its negative environmental impact and in its essential natural values, such as water, land and ecosystems.

To be able to achieve this aim, the efficiency of the multimodal logistic chains must be improved, even increasing the use of internally sustainable methods, when other technological innovations can be insufficient (for example, longdistance freight transportation). The EU needs freight transportation corridors specially developed and optimized when talking about the use of energy and emissions, which will minimize the environmental impacts, but at the same time are attractive because of their reliability, partial traffic jams, and reduced administrative and functioning costs. The question is to guarantee a structural change that allows the railway to compete and absorb a significantly bigger proportion of freight in long and medium distances.

Coloma (2015d) carried out an high-impact socioeconomic study about the Cofemanex concluding that the infrastructure investments of railway freight transport have a positive impact in the economic growth, creating wealth, job vacancies and rise commercial trades.

In this investigation an exhaustive and complete analysis of the actions needed for the commissioning and later upgrade of the Cofemanex has been carried out. All infrastructure and exploitation determinants to be able to do the passenger and freight transport are analysed. The total investment needed is $240,731,223.41 €$. In this way it would be able to have an upgraded freight railway corridor as the European TSIs requires. Since the Badajoz-Puertollano station corridor has a length of $298.6 \mathrm{~km}$, a final investment of $806,199.68 € / \mathrm{km}$ is required. The exclusive cost of the construction of an upgraded freight railway line is reduced to a $191,316,412.9 €$. With this new total we can estimate the cost of one railway kilometre in the Cofemanex in $640,711.36 € / \mathrm{km}$. 
The necessary cost for the construction of the platform (without installation, signposting or electrification of the line) in the new high-speed line Madrid-Extremadura rises up the total of $5.76 \mathrm{M} € / \mathrm{km}$. Even in the more economic stretch Montijo-Badajoz) has a cost of 3.19 M€ / km (Coloma, 2015e).

It can be concluded that the unitary cost of an upgraded railway freight corridor between Badajoz-Puertollano, including a superstructure, signposting, electrification and logistic installations, is 5 times inferior than the exclusive construction in the most favourable stretch of the Extremaduran high speed line, and 9 times inferior than the unitary average cost of its construction. If to the necessary costs of construction of the platform we add the supplies and installation of the sleepers and railway (1 M€ $/ \mathrm{km}$ approximately), the electrification of the railway $(0.75 \mathrm{M} € / \mathrm{km})$ and the ERTMS signposting $(1 \mathrm{M} € / \mathrm{km})$ the unitary average cost of the high-speed line Madrid-Extremadura rises up to $8.51 \mathrm{M} € / \mathrm{km}$. This means that the construction of a kilometre of upgraded freight line construction costs 13 times less than a kilometre of high-speed line, or in other words, with the money of 1 high-speed railway kilometre we can upgrade more than 13 $\mathrm{km}$ of upgraded freight rail lines.

\section{Acknowledgements.}

This article has been the result of the Collaboration Agreement between the Junta de Extremadura and the University of Extremadura for "The development of an Investigation Project about the adaptation of the current railway line, Ciudad Real-Badajoz, in its Extremaduran route, to a highly-efficient rail freight transport line in Extremadura and the analysis of the environmental and economic consequences of the Extremaduran region“.

\section{References.}

ADIF (1998). “Geometría de la vía. N.A.V. 0-2-0.0. Parámetros geométricos”. 1998.

ADIF (2014a). Cuadro de velocidades máximas de la línea 520 Ciudad Real-Badajoz. 2014

ADIF (2014b). Relación entre la carga máxima (t) y la rampa característica (\%o) para los distintos tipos de locomotora de mercancías. 2014

COLOMA, J.F. (2015a). "Trazado en planta del Cofemanex". Aspectos ingenieriles y técnicos de la construcción de la línea ferroviaria de mercancías de altas prestaciones en Extremadura y su efecto en la competitividad económica extremeña. Tesis Doctoral. Universidad de Extremadura. Cáceres (España), pp. 324-357. < http://dehesa.unex.es/handle/10662/3194 > [Consulta 21 de enero de 2016].

COLOMA, J.F. (2015b). "Trazado en alzado del Cofemanex“. Aspectos ingenieriles y técnicos de la construcción de la línea ferroviaria de mercancías de altas prestaciones en Extremadura y su efecto en la competitividad económica extremeña. Tesis Doctoral. Universidad de Extremadura. Cáceres (España), pp. 358-373. <http://dehesa.unex.es/handle/10662/3194> [Consulta 21 de enero de 2016].

COLOMA, J.F. (2015c). "Anexo IV. Fichas de estructuras del Cofemanex “. Aspectos ingenieriles y técnicos de la construcción de la línea ferroviaria de mercancías de altas prestaciones en Extremadura y su efecto en la competitividad económica extremeña. Tesis Doctoral. Universidad de Extremadura. Cáceres (España). < http://dehesa.unex.es/handle/10662/3194 > [Consulta 21 de enero de 2016].

COLOMA, J.F. (2015d). "Parte II. Estudio socioeconómico“. Aspectos ingenieriles y técnicos de la construcción de la línea ferroviaria de mercancías de altas prestaciones en Extremadura y su efecto en la competitividad económica extremeña. Tesis Doctoral. Universidad de Extremadura. Cáceres (España), pp. $795-832 . \quad<$ http://dehesa.unex.es/handle/10662/3194 > [Consulta 21 de enero de 2016].

COLOMA, J.F. (2015e). "Costes de la línea de alta velocidad Madrid-Extremadura ". Aspectos ingenieriles y técnicos de la construcción de la línea ferroviaria de mercancías de altas prestaciones en Extremadura y su efecto en la competitividad económica extremeña. Tesis Doctoral. Universidad de Extremadura. Cáceres (España), pp. 263-268. < http://dehesa.unex.es/handle/10662/3194 > [Consulta 21 de enero de 2016].

EU (2001). European Union. White Paper. European transport policy for 2010: time to decide. 2001.

EU (2010). European Union. Regulation (EU) No 913/2010 of the European parliament and of the council of 22 September 2010 concerning a European rail network for competitive freight. 2010.

EU (2011a). European Union. Commission Decision of 26 April 2011 concerning a technical specification for interoperability relating to the 'infrastructure' subsystem of the trans-European conventional rail system. 2011. 
EU (2011b). European Union. "White Paper. Roadmap to a Single European Transport Area - Towards a competitive and resource efficient transport system ". 2011.

EU (2013). European Union. Regulation (EU) N $N^{\circ} 1316 / 2013$ of the european parliament and of the council of 11 December 2013 establishing the Connecting Europe Facility, amending Regulation (EU) No 913/2010 and repealing Regulations (EC) No 680/2007 and (EC) No 67/2010. 2013

M.FOMENTO (2011). Resolución de la Secretaría de Estado de Planificación e Infraestructuras, sobre criterios de diseño de líneas ferroviarias para el fomento de la interoperabilidad y del tráfico de mercancías. 2011

UNE (2014). UNE-EN 15273-3:2.014. Aplicaciones ferroviarias. Gálibos. Parte 3: Gálibo de implantación de obstáculos. 2014 